\title{
Socio-economic perspectives on the conservation of Critically Endangered vultures in South Asia: an empirical study from Nepal
}

\author{
NABIN BARAL and RAMJI GAUTAM
}

\begin{abstract}
Summary
Following the catastrophic decline in populations of three species of South Asian Gyps vultures, we conducted a study to explore socio-economic variables that could facilitate conservation efforts. A questionnaire survey was carried out in 103 randomly selected households in the Rampur valley, one of the Important Bird Areas of Nepal, during 2004. Among respondents, $38 \%$ were female, $62 \%$ male, $28 \%$ illiterate and $72 \%$ literate. Households belonged to three ethno-religious groups (Hindu castes, ethnic groups and Muslim) and $96 \%$ of households had some parcels of registered land to farm. About $90 \%$ of households reared one or more types of livestock while the mean Livestock Size Unit was 3.32 per household. Livestock diseases and ailments were common and usually treated with diclofenac. Livestock carcass disposal practices were favourable to vultures because $60 \%$ of households dumped carcasses in open fields. Diclofenac is lethal to vultures; $3 \%$ of diclofenac-contaminated carcasses were available annually. The majority $(78 \%)$ of respondents had favourable attitudes towards the concept of vulture conservation. Diclofenac contamination and the destruction of nesting habitat were two major threats to vultures. Ensuring healthy food through economic incentives, inculcating new values through environmental education and soliciting popular participation for habitat conservation are recommended.
\end{abstract}

\section{Introduction}

There has been a catastrophic decline in populations of three Gyps vultures in the Indian subcontinent (Prakash 1999, Virani et al. 2002, Prakash et al. 2003). In the wake of the population crash, three species - White-rumped Vulture G. bengalensis, Long-billed Vulture G. indicus and Slender-billed Vulture G. tenuirostris - were reclassified as Critically Endangered, placing them among the species most threatened with global extinction (BirdLife International 2001). Vultures have also disappeared from many parts of their former ranges due to food shortages and loss of habitat (Pain et al. 2003). However, the recent disappearance is attributed to the veterinary use of the pharmaceutical diclofenac. Research in Pakistan has shown that diclofenac, a widely used painkiller and anti-inflammatory drug administered to livestock and humans, can cause mortality in vultures (Oaks et al. 2004). Evidence from India and Nepal also supports the diclofenac hypothesis (Shultz et al. 2004, Prakash et al. 2005). Widespread use of veterinary diclofenac in the current vulture range is expected but thus far there has been no attempt to quantify the extent of its use, nor is there any evidence of the actual magnitude of vulture exposure to diclofenac. Therefore, the survival of vultures depends on diclofenac dynamics, government policies on its regulation, and attitudes of stakeholders towards vulture conservation. 
To understand which vulture conservation strategies might be effective and how they could be implemented, it is important first to understand the main characteristics of local people that may influence conservation attitudes, habitat conservation and resource use, and livestock management. For some time, social scientists carried out research targeted at understanding how attitudes are formed and what factors are significant predictors of attitudes. Perceived personal costs and benefits influence attitude formation (Heinen 1993, Mehta and Heinen 2001). In addition, Ite (1996) grouped variables into four factors - social, cultural, political and economic which he argued largely determine attitudes towards conservation. With reference to culture, it has been suggested that religion encourages high regard for wildlife in some parks of India, and local people have shown favourable attitudes to conservation in spite of substantial economic loss due to wildlife damage (Sekhar 1998). Migration of people is an additional influential social variable that frequently disrupts ecosystems (Schreckenberg 1999), and leads to failure of conservation initiatives (Southgate and Clark 1993, Oates 1995, Noss 1997). Economic incentives also play an important role in conservation attitudes and, in many cases, people who receive goods and services personally from conservation programmes have more favourable attitudes than others who do not (Newmark et al. 1993). Regardless of what factors influence attitudes, it is argued that they are decisive in achieving conservation goals (Heinen 1996, Richards 1996).

Throughout the South Asian region, vultures benefit from religious beliefs. Concepts of universal compassion in Buddhism, allegiance to Karma in Hinduism and sacred sky burial in Zoroastrianism have all given religious value to vultures as sentient beings. Their specific functions such as disposing of human corpses in sky burial or funeral rites and scavenging carcasses were taken for granted when their densities were high. The unprecedented decline in vulture populations has highlighted cultural, ecological, economic and public health implications. Recognizing the urgency of the problem, two international summits were held in February 2004 to avert the imminent threat of global extinction (Anonymous 2004). These meetings recommended a three-pronged approach: a ban on the use of veterinary diclofenac, captive breeding and release, and a massive conservation awareness programme, which should be implemented with great urgency. In both meetings, biological aspects of conservation received more attention than socio-economic aspects, but both biological and socio-economic perspectives should receive equal attention to ensure the sustainability of a conservation programme for endangered species.

We conducted a household survey in one of the Important Bird Areas of Nepal, the Rampur valley, during summer 2004 to add a new perspective to vulture research, i.e. the integration of socio-economic aspects. We present results that help to assess predictors of conservation attitudes and livestock holdings, and a strategy to secure safe food for vultures. Although the Indian government announced its intention to ban the veterinary use of diclofenac (Swan et al. 2006), it is unlikely that other states within the vulture's range would do the same immediately, based on the precautionary principle. Therefore we recommend large-scale awareness programmes for stakeholders at all levels, from local to international.

\section{Study area and methods}

The Rampur valley $\left(27^{\circ} 51^{\prime} 80^{\prime \prime} \mathrm{N}\right.$ and $83^{\circ} 54^{\prime} 24^{\prime \prime}$ E) lies in south-west Nepal approximately $370 \mathrm{~km}$ from Kathmandu. It is situated in the transitional region of the lowland terai and midhills ecological zones at $442 \mathrm{~m}$ mean elevation. The valley has absorbed large numbers of people over the past four decades because of its fertile lands. It has a good degree of grassroots organization, with 56 forest user groups of which 44 are managing, conserving and utilizing parcels of forest under the community forestry program (DDC 2000). The climate of the area is subtropical with three distinct seasons: hot-dry from February to May, monsoon from June to August and cool-dry from September to January. The vegetation comprises subtropical species, and vultures mostly use kapok Bombax ceiba trees for roosting and nesting. Vultures found in the area include: White-rumped Vulture, Slender-billed Vulture, Red-headed Vulture Sarcogyps 
calvus, and Egyptian Vulture Neophron percnopterus. The valley has the highest density of breeding White-rumped Vultures (Baral et al. 2005); therefore, it has been included in the list of Important Bird Areas of Nepal (Inskipp and Baral 2005).

We administered a structured questionnaire survey to a sample of 103 randomly selected households living within a $2 \mathrm{~km}$ radius of vulture colonies during summer 2004. We randomly selected respondents from archives of community forest user groups. Taking into account the low literacy rate in rural Nepal, questionnaires were written in Nepali (the national language of Nepal) and administered orally. Local words were used and technical jargon was avoided. One adult person ( $\geqslant_{1} 8$ years old) in each household was interviewed in his or her residence. Usually, household heads were interviewed; in their absence, any family members willing to participate were interviewed. Each questionnaire was divided into five general parts: (I) ethno-religious background, household characteristics (gender, age and occupation of all household members), education and migration; (2) economic activities such as land-holdings, alternative sources of income, annual cash income; (3) agriculture and animal husbandry (types of manure, pesticide use, organic farming, livestock holdings, animal diseases, veterinary services and carcass disposal practices); (4) natural resource use, and (5) awareness about the plight of vultures and attitudes towards their conservation. Most questions were closed-ended, although some open-ended contingency questions were included. The questionnaire was pre-tested on five households and necessary changes were made for clarity.

Means of quantitative variables were presented with I standard deviation. One- and twosample $t$-tests were used to compare means of quantitative variables. The chi-square test was used for testing associations between categorical variables. A binomial probability test was used to compare proportions of dichotomous variables. Since the values of different livestock and their contribution to vulture diet vary, the number of livestock per household was expressed using the Livestock Size Unit (LSU). Since a $400 \mathrm{~kg}$ steer is equivalent to I LSU (Raut 1997), in the present study, I adult buffalo (I LSU) was considered equivalent to I steer, and one immature buffalo, cow, calf, pig, and sheep or goat was equivalent to $0.5,0.8,0.4,0.3$ and 0.2 steer, respectively. Poultry and domestic dogs were not included in the LSU calculation. A significant proportion of vulture diet comes from livestock. Therefore, we were interested to explore what factors determine livestock holdings; thus, we built a multiple regression model taking the LSU as the response variable. We hypothesized that respondents with large land-holdings and family size would tend to keep many livestock, while the reverse would be true for respondents engaged in off-farm income. Off-farm income was recorded as a dummy variable with two categories: 'yes $=I^{\prime}$ and 'no $=0^{\prime}$.

\section{Results}

Of 103 respondents, $38 \%$ were female and $62 \%$ were male. Age of the respondents ranged from 18 to 75 years. The median age was 36 and the mean age was $36.7 \pm 12.4$ years. There was no significant difference in the age of men $(37.4 \pm 12.3)$ and women $(35.6 \pm 12.5 ; t=-0.71, P>$ 0.05). The education level of respondents was categorized into four groups: illiterate, those who cannot read or write; primary, those having $1-5$ years of formal education; secondary, those having 5-10 years of formal education; and college, those having associate and undergraduate degrees. Twenty-eight per cent of the respondents were illiterate, while $16 \%$ had primary, $41 \%$ had secondary and $15 \%$ had college-level education. Men were more educated than women $\left(\chi_{2}^{2}\right.$ $=10.77, P<0.05)$. Respondents belonged to three ethno-religious groups: Hindu castes (Brahman and Chhetri 60\%, and Occupational 10\%); ethnic groups (Newar 3\%, and Magar and Kumal $14 \%$ ); and Muslim (13\%). The largest proportion of respondents (68\%) was made up of farmers, followed by teachers (12\%), students $(8 \%)$, businessmen $(8 \%)$ and manual labourers $(4 \%)$. Most illiterate respondents $(96 \%)$, and all respondents belonging to occupational castes, were engaged in agriculture $\left(\chi_{2}^{2}=22.61, P<0.001\right)$. An overwhelming proportion $(88 \%)$ of 
the respondents had migrated from mountain districts within past 40 years due to lack of fertile lands.

Land-holding was classified into three groups: small holders with less than 0.5 ha, medium holders with $0.5^{-2}$ ha, and large holders who have more than 2 ha of land (CBS 2001). Almost all (96\%) households had on average $0.62 \pm 0.45$ ha of land (range $0.01-2.44$ ha) with title. The highest proportion $(58 \%)$ of respondents belonged to medium holders ( $0.85 \pm 0.37$ ha), followed by small holders (41\%; $0.27 \pm 0.17$ ha) and large holders ( $1 \% ; 2.44$ ha). A majority $(81 \%)$ of respondents said that they use both organic manure and chemical fertilizer as the situation demands. Around $69 \%$ of households had used pesticides frequently while $31 \%$ had not. Commonly used pesticides were BHC, Aldrin, Malathion, Metacid and Thiodan.

Around $90 \%$ of households had one or more kinds of livestock. The most preferred livestock species was buffalo, followed by goat and sheep, oxen, cow, calf and pig (Figure 1). The mean LSU per household was $3.32 \pm 1.93$ and ranged from 1 to 10 . The results of a linear regression model showed that the explanatory variables explained about $17 \%$ of variability in the LSU (Table 1 ). The respondents who had larger land-holdings and bigger family size were more likely to keep more livestock than others $(P<0.05)$. Although statistically not significant, the negative coefficient of the off-farm income variable suggested that respondents who were not subsistence farmers tended to keep few livestock $(P>0.05)$.

Black quarter, tympany (bloot), foot and mouth disease, haemorrhagic septicaemia, ephemeral fever, asthma and mange were reported to be common diseases among livestock or poultry. Diclofenac is widely used in any disease condition characterized by pain, fever and inflammation, but not in tympany and mange (Dr D. N. Dhungana, pers. comm. 2004). Within the past 5 years, $35 \%$ of households lost livestock to disease. More than half $(55 \%)$ of diseased livestock die in the absence of modern veterinary health care $(z=-0.52, P>0.05)$. When veterinary personnel (doctors and assistants) visited ailing livestock, diclofenac was administered in $45 \%$ of cases. Since $36 \%$ of diseased carcasses were buried, and assuming that $45 \%$ of diseased livestock were treated with diclofenac, annually $3 \%$ of contaminated carcasses were available to vultures.

When livestock died, $60 \%$ of households threw carcasses into open fields while $22 \%$ buried them and $18 \%$ called cobblers to skin carcasses. There was a significant association between carcass disposal practices and mode of livestock death $\left(\chi_{2}^{2}=5.98, P=0.05\right.$; Table 2). When livestock succumbed to diseases, local people were more likely to bury the carcass than when natural deaths occurred. In cases of natural death, people preferred either to dump carcasses in

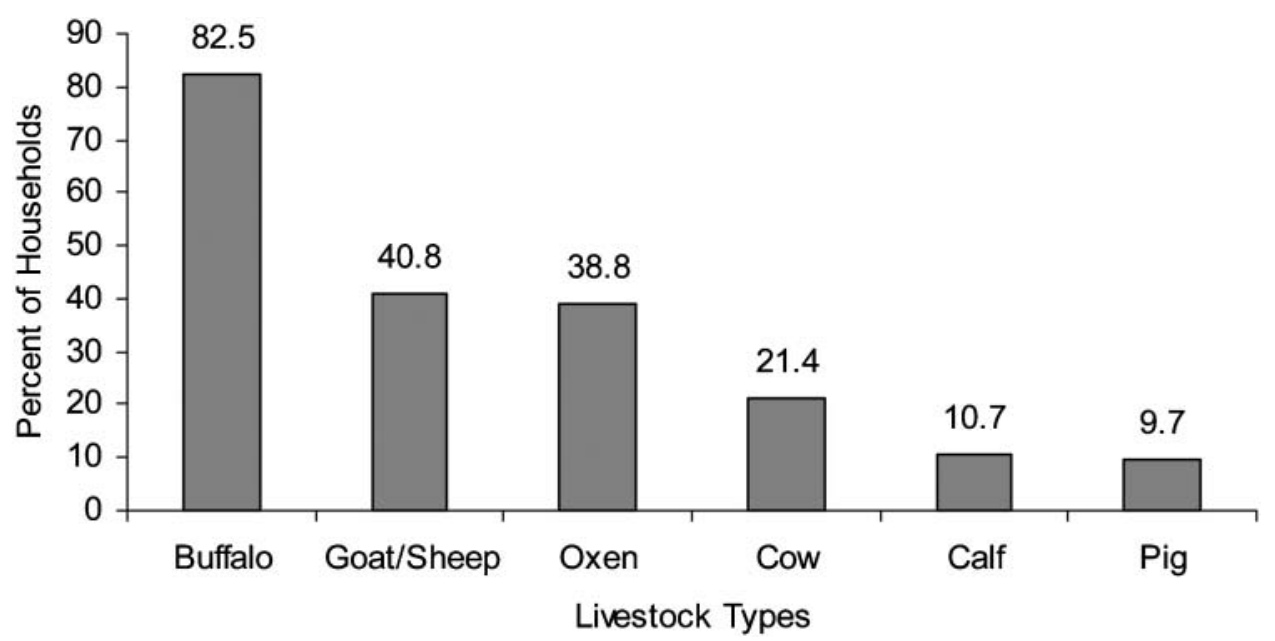

Figure 1 . Percentage of households raising different types of livestock. 
Table 1. Multiple regression of Livestock Size Unit (LSU) on family size, land-holdings and off-farm income.

\begin{tabular}{lclcl}
\hline LSU & Coefficient & Standard error & $t$-statistics & $P \mid$ \\
\hline Family size & 0.178 & 0.081 & 2.20 & 0.030 \\
Land-holdings & 1.167 & 0.450 & 2.59 & 0.011 \\
Off-farm income $\left(\right.$ Yes $^{-1}$ ) & -0.468 & 0.314 & -1.49 & 0.139 \\
\hline
\end{tabular}

$F_{3,89}=5.94, P=0.001, R^{2}=17 \%$.

Table 2. Cross-tabulation of livestock disease and carcass disposal practices.

\begin{tabular}{lclcll}
\hline Animal diseases & Buried & Thrown out & Skinned by cobbler & Total & Test \\
\hline No & 9 & 41 & 12 & 62 & $\chi^{2}=5.98$ \\
Yes & 12 & 16 & 5 & 33 & $P=0.05$ \\
Total & 21 & 57 & 17 & 95 & d.f. $=2$ \\
\hline
\end{tabular}

open fields or call cobblers to skin them. Whether cobblers consumed the meat depended on the type of livestock, season, and availability of human resources to process them.

Conservation attitudes were measured by 13 dichotomous (agree or disagree) statements. Statements covered the population status of vultures, carcass availability, hunting of vultures, habitat conservation and community forestry, education and awareness, religious perspectives, intergenerational equity, chemical fertilizers and pesticides use, and population trends of feral dogs. If respondents agreed, then one point was given to that statement and if they disagreed no point was given. The reverse was true for one negative statement. The maximum points a respondent could score was 13 . Respondents scoring fewer than 7 were considered to have unfavourable attitudes (o) while those scoring 7 or more points were considered to have favourable attitudes (I)

The results showed that the majority $(78 \%)$ of respondents had favourable attitudes towards vulture conservation $(P<0.05)$. Local people were aware of dwindling vulture populations, but they did not agree with the fact that there has been mass mortality (Table 3). A significant proportion $(77 \%)$ of respondents said that there has been no increase in the number of carcasses $(P<0.05)$. Local people had not killed vultures. More than $90 \%$ of respondents were in favour

Table 3. Attitude statements and percentage of respondents agreeing or disagreeing with each statement. This is used to measure overall conservation attitude.

\begin{tabular}{llll}
\hline $\begin{array}{l}\text { Statement } \\
\text { no. }\end{array}$ & Statement & Agree & Disagree \\
\hline 1 & Vultures are declining in your area & 87 & 13 \\
2 & In recent years, there has been mass mortality of vulture population & 18 & 82 \\
3 & There are more carcasses than 5 years ago & 23 & 77 \\
4 & Other people kill vultures & 18 & 82 \\
5 & It is important to set aside a place for vultures to live in & 95 & 5 \\
6 & It is important to educate people about vulture conservation & 92 & 8 \\
7 & We should conserve vultures for our future generation to see & 95 & 5 \\
8 & People have high regard for vultures due to religious reasons & 38 & 62 \\
9 & Vultures are beneficial to humans & 74 & 26 \\
10 & Forests around your village have decreased in recent years & 67 & 33 \\
11 & Chemical fertilizers and pesticides may cause vulture decline & 55 & 45 \\
12 & It would be better not to have community forests ${ }^{a}$ & 12 & 88 \\
13 & There are more feral dogs now than 10 years ago & 49 & 51 \\
\hline
\end{tabular}

${ }^{a}$ Negative statement. 
Table 4. Association of conservation attitudes with socio-economic variables.

\begin{tabular}{llll}
\hline Variables & $\chi^{2}$ & d.f. & $P$ \\
\hline Gender & 2.58 & 1 & 0.108 \\
Ethnicity & 2.74 & 3 & 0.434 \\
Education & 4.94 & 2 & $0.084^{a}$ \\
Occupation & 0.31 & 2 & 0.858 \\
Landholdings & 3.64 & 1 & $0.056^{a}$ \\
Cash income & 1.25 & 3 & 0.742 \\
Participation & 1.31 & 1 & 0.252 \\
\hline
\end{tabular}

${ }^{a}$ Significant at the $10 \%$ error level.

of protecting habitats, educating people and emphasizing intergenerational equity for vulture conservation. Although local people did not have high regard for vultures on religious grounds, they considered them as beneficial to humans $\left(\chi_{1}^{2}=5.82, P<0.05\right)$. People were aware of declining forests in their surroundings and were in favour of community forestry $(z=8.13, P<$ 0.001). Respondents seemed to relate vulture decline with the use of chemical fertilizers and pesticides $\left(\chi^{2}{ }_{1}=6.27, P<0.05\right)$. There was no significant association of conservation attitudes with socio-economic variables (e.g. gender, ethnicity, occupation and cash income; $P>0.10$; Table 4). However, at the 10\% error level, education level and land-holdings were predictors of conservation attitudes.

\section{Discussion}

The higher proportion of male to female respondents was as expected. In the socio-political context of South Asia, there is an asymmetrical distribution of decision-making power; men generally decide household and social affairs. In rural areas, women are mostly bound to household chores and usually decline to be interviewed if men are present. Additionally, we targeted the family head for interviews and these are usually men.

Education can affect conservation attitudes, usually for the better (Heinen 1993, Fiallo and Jacobson 1995, Gillingham and Lee 1999). In the present study, education had significant association with gender, ethnicity and occupation. The illiteracy rate among women, occupational castes and ethnic groups was higher than men and higher Hindu castes, respectively. An environmental education programme for these groups is imperative. Occupational castes and ethnic groups should be the target groups to solicit beneficial actions for vulture conservation, because they have important roles in carcass management.

The influx of people into the valley started after malaria eradication in the 1960s. Escalating pressures on natural resources due to migration may compromise roosting and nesting sites for vultures. Firewood was the most important resource because $80 \%$ of households still rely on it. To supplement energy needs, $44 \%$ of households had installed biogas. Biogas plants help to reduce firewood consumption by over half (Adhikari 2002) and serve as an incentive to local people to keep large numbers of livestock that in turn may help secure more carcasses for vultures.

The productivity of land is good; $67 \%$ of respondents stated that they had enough produce to sustain themselves even though parcels are small compared with the national average (o.96 ha; $t=-7.41, P<0.001$ ). Livestock rearing is an integral part of subsistence agriculture, and animals kept for milk, meat, manure and draught. The mean LSU (3.32) was significantly lower than recorded in the western terai of Nepal (4.18; $t=-4.28, P<0.001$; Baral 2005). People with larger land-holdings have more resources and larger numbers of livestock needed for ploughing and manure. Households with large family sizes also have more human resources to use in livestock rearing. As hypothesized, the results are consistent in the context of the political, socioeconomic and ecological milieu of South Asia. 
Veterinary health care facilities are under-developed but rapidly increasing in South Asia. Within the past 5 years, a total of 70 livestock died of which 33 were diseased. Fifteen died after treatment; 5 were buried and, therefore, 1o contaminated carcasses were available to vultures in this area. A simulation model of vulture demography predicts that only a small proportion $\left(<_{1} \%\right)$ of available carcasses needs to be contaminated with a lethal level of diclofenac to have caused the observed decline (Green et al. 2004). Considering the availability of $3 \%$ contaminated carcasses, we cannot rule out the diclofenac hypothesis even though we do not know the lethal levels in them. Recent research shows the residue of diclofenac in dead vultures from Rampur (Shultz et al. 2004). Although carcass disposal practices are favourable to vultures, this makes them vulnerable to contamination. When livestock die of diseases, local people are more likely to bury them, but this is done to prevent the potential spread of disease to their livestock and not for preventing vulture deaths. Vultures frequent human habitation for food and positive changes in carcass disposal practices are important to safeguard contamination. Providing economic incentives to local people to bury all contaminated carcasses and environmental education about threats posed by veterinary diclofenac to stakeholders may help to secure uncontaminated food for vultures.

The majority of respondents had favourable attitudes towards the concept of vulture conservation. Conservation attitudes are influenced by socio-economic variables such as gender, ethnicity, education, occupation, household affluence and participation in conservation (Infield 1988, Fiallo and Jacobson 1995, Mehta and Kellert 1998, Gillingham and Lee 1999, Sah and Heinen 2001); however, none of these variables was a significant predictor of attitudes in this study. Favourable attitudes may not be positively correlated with beneficial action in that, although people were aware of dwindling populations of vultures and were in favour of habitat conservation, their actions were detrimental to vultures. Community forest user groups were logging kapok trees, which are the main roosting and nesting sites for vultures. In 2003, of 120 mature kapok trees in the study area, 40 were logged to support a community school, an action that may seriously compromise breeding (Baral et al. 2005). People like the concept of conservation, but the process conflicts with their basic needs. Local support for community forestry is likewise not directly linked with vulture conservation. Religious values were nearly significant predictors of whether people kill vultures $\left(\chi_{1}^{2}=2.90, P=0.068\right)$.

From mythological times to the present, vultures have held a special role in human society. Their role in stopping the spread of diseases and its human health implications have been brought to the fore (Prakash et al. 2003). The mutualism between people and vultures is of paramount importance for ecosystem function. Along with ecological and economic components, a social dimension should be integrated in a systems approach for long-term vulture conservation. Animal husbandry practices, livestock health and human attitudes are all important variables that play significant roles in securing uncontaminated food for vultures.

\section{Acknowledgements}

The Oriental Bird Club, U.K., and The Peregrine Fund, U.S.A., provided funds to carry out this research. We thank Drs Joel Heinen, David Bray, Munir Virani and Richard Cuthbert, and Ms Carol Inskipp for their insightful comments and suggestions on earlier versions of the paper. We appreciate the help of Ram Chandra Lamshal, Binod Adhikari, Sushil Dahal, Shiva Adhikari, Gorkarna Adhikari and Bhim Raj Poudel during the fieldwork. Also, we are grateful to the local people who showed interest in our research and patiently answered the questions.

\section{References}

Adhikari, R. K. (2002) Impact of biogas programme on forest conservation: a case study from Suryapatuwa VDC of the south-western buffer zone of RBNP, 
mid-western Nepal. Unpublished B.Sc. thesis, Institute of Forestry, Pokhara.

Anonymous (2004) Report of the International South Asian Vulture Workshop, 12-14 February 2004, Parwanoo, India. URL: http//www.vulturerescue.org/.

Baral, N. (2005) Resources use and conservation attitudes of local people in the western terai landscape, Nepal. Unpublished M.Sc. thesis, Florida International University, Miami, FL, U.S.A.

Baral, N., Gautam, R. and Tamang, B. (2005) Population status and breeding ecology of White-rumped Vulture Gyps bengalensis in Rampur Valley, Nepal. Forktail 21: 87-91.

BirdLife International (2001) Threatened birds of Asia: the BirdLife International Red Data Book. Cambridge, U.K.: BirdLife International.

CBS (2001) Statistical year book of Nepal 2001. Kathmandu, Nepal: Central Bureau of Statistics.

DDC (200o) District profile of Palpa. Palpa District Development Committee, Tansen, Palpa.

Fiallo, E. A. and Jacobson, S. K. (1995) Local communities and protected areas: attitudes of rural residents towards conservation and Machalilla National Park, Ecuador. Env. Conserv. 22: 241-249.

Gillingham, S. and Lee, P. C. (1999) The impact of wildlife-related benefits on the conservation attitudes of local people around the Selous Game Reserve, Tanzania. Env. Conserv. 26: 218-228.

Green, R. E., Newton, I., Shultz, S., Cunningham, A. A., Gilbert, M., Pain, D. J. and Prakash, V. (2004) Diclofenac poisoning as a cause of vulture population declines across the Indian subcontinent. J. Appl. Ecol. 41: 793-800.

Heinen, J. T. (1993) Park-people relations in Koshi Tappu Wildlife Reserve: a socioeconomic analysis. Env. Conserv. 20: 25-34.

Heinen, J. T. (1996) Human behaviour, incentives and protected area management. Conserv. Biol. 10: 681-684.

Infield, M. (1988) Attitudes of a rural communities towards conservation and a local conservation area in Natal, South Africa. Biol Conserv. 45: 21-46.

Inskipp, C. and Baral, H. S. (2005) Important Bird Areas in Nepal: key sites for bird conservation. Kathmandu, Nepal: Bird Conservation Nepal.

Ite, U. E. (1996) Community perceptions of the Cross River National Park, Nigeria. Env. Conserv. 23: 351-357.

Mehta, J. N. and Heinen, J. T. (2001) Does community-based conservation shape favourable attitudes among locals? An empirical study from Nepal. Env. Manage. 28: 165-177.

Mehta, J. N. and Kellert, S. R. (1998) Local attitudes toward community-based conservation policy and programmes in Nepal: a case study of the Makalu-Barun Conservation Area. Env. Conserv. 25: 320-333.

Newmark, W. D., Leonard, N. L, Sariko, H. I. and Gamassa, D. G. M. (1993) Conservation attitudes of local people living adjacent to five protected areas in Tanzania. Biol. Conserv. 63: 177-183.

Noss, A. J. (1997) Challenges to nature conservation with community development in central African forests. Oryx 31: $180-188$.

Oaks, J. L., Gilbert, M., Virani, M. Z., Watson, R. T., Meteyer, C. U., Rideout, B. A., Shivaprasad, H. L., Ahmed, S., Chaudry, M. J. I., Arsad, M., Mahmood, S., Ali, A. and Khan, A. A. (2004) Diclofenac residues as the cause of population decline of vultures in Pakistan. Nature 427: 630-633.

Oates, J. F. (1995) The dangers of conservation by rural development: a case-study from the forests of Nigeria. Oryx 29: 115-122.

Pain, D. J., Cunningham, A. A., Donald, P. F., Duckworth, J. W., Houston, D. C., Katzner, T., Parry-Jones, J., Poole, C., Prakash, V., Round, P. and Timmins, R. (2003) Causes and effects of temporospatial declines of Gyps vultures in Asia. Conserv. Biol. 17: 661-671.

Prakash, V. (1999) Status of vultures in Keoladeo National Park, Bharatpur, Rajasthan, with special reference to population crash in Gyps species. J. Bombay Nat. Hist. Soc. 96: 365-378. 
Prakash, V., Pain, D. J., Cunningham, A. A., Donald, P. F., Prakash, N., Verma, A., Gargi, R., Sivakumar, S. and Rahamani, A. R. (2003) Catastrophic collapse of Indian white-backed Gyps bengalensis and longbilled Gyps indicus vulture populations. Biol. Conserv. 109: 381-390.

Prakash, V., Green, R. E., Rahmani, A. R., Pain, D. J., Virani, M. Z., Khan, A. A., Baral, H. S., Jhala, Y. V., Naoroji, R., Shah, N., Bowden, C. G. R., Choudhury, B. C., Narayan, G. and Gautam, P. (2005) Evidence to support that diclofenac caused catastrophic vulture population decline. Curr. Sci. 88: 1533-1534.

Raut, Y. (1997) Concept of stocking rate and carrying capacity: high stocking rate and its effects on pasture production and ecology. Pp. $16-34$ in A text book of animal husbandry. Volume I: Pasture production. Kathmandu, Nepal: The Department of Livestock Services, Ministry of Agriculture.

Richards, M. (1996) Protected areas, people and incentives in the search of sustainable forest conservation in Honduras. Env. Conserv. 23: 207-217.

Sah, J. P. and Heinen, J. T. (2001) Wetland resource use and conservation attitudes among indigenous and migrant peoples in Ghodaghodi Lake area, Nepal. Env. Conserv. 28: 345-356.

Schreckenberg, K. (1999) Products of managed landscape: non-timber forest products in the parklands of the Bassila region, Benin. Global Ecol. Biogeog. 8: 279-289.

Sekhar, N. U. (1998) Crop and livestock depredation caused by wild animals in protected areas: the case of Sariska Tiger Reserve, Rajasthan, India. Env. Conserv. 25: 160-171.

Shultz, S., Baral, H. S., Charman, S., Cunningham, A. A., Das, D., Ghalsasi, G. R., Goudar, M. S., Green, R. E., Jones, A., Nighot, P., Pain, D. J. and Parkas, V. (2004) Diclofenac poisoning is widespread in declining vulture populations across the Indian subcontinent. Proc. R. Soc. Lond. B (Suppl.) DOI 10.1098/rsbl.2004.0223.

Southgate, D. and Clark, H. L. (1993) Can conservation projects save biodiversity in South America? Ambio 22: 163-166.

Swan, G and 16 others (2006) Removing the threat of diclofenac to Critically Endangered Asian vultures. PLoS Biology, DOI: 10.1371/journal.pbio.0040066.

Virani, M. Z., Gilbert, M., Watson, R., Oaks, J. L., Chaudhry, J., Arsad, M., Ahmed, S., Mahmood, S., Ali, A., Baral, H. S. and Giri, J. B. (2002) Breeding and mortality of Oriental White-backed Vultures Gyps bengalensis: summary of results of a twoyear study in Pakistan and Nepal (2000/ 2001 and 2001/2002). Pp. 1-3 in T. Katzner and J. Parry-Jones, eds. Reports from the workshop Conservation of Gyps vultures in Asia. New Orleans, USA: Third North American Ornithological Conference.

\section{NABIN BARAL ${ }^{*} \dagger$}

Department of Environmental Studies, Florida International University, Miami, FL 33199, USA.

\section{RAMJI GAUTAM}

Department of Zoology, Prithvi Narayan Campus, Pokhara, Nepal.

*Corresponding author; e-mail:nbaral@gmail.com

$\dagger$ Current address: Virginia Polytechnic Institute and State University, Department of Forestry, 305 Cheatham Halls, Blacksburg, VA 24061, USA 